\title{
Mil Vezes Boa Noite
}

\section{1,000 Times Good Night}

\section{Mil veces buenas noches}

Ariélly Cristina Fidelis | arielly.psi@gmail.com

Fundação Oswaldo Cruz, Escola Politécnica de Saúde Joaquim Venâncio, Programa de Pós-Graduação em Educação Profissional em Saúde, Rio de Janeiro, RJ, Brasil.

Carlos Eduardo Freire Estellita-Lins | cefestellita@gmail.com

Fundação Oswaldo Cruz, Instituto de Comunicação e Informação Científica e Tecnológica em Saúde, Rio de Janeiro, RJ, Brasil.

Arlinda B. Moreno | morenoar@fiocruz.br

Fundação Oswaldo Cruz, Escola Nacional de Saúde Pública Sérgio Arouca, Departamento de Epidemiologia e Métodos Quantitativos em Saúde, Rio de Janeiro, RJ, Brasil.

\section{Sinopse}

Rebecca (Juliette Binoche) é uma das mais prestigiadas fotojornalistas de guerra no mundo, famosa por registrar imagens perigosas e assustadoras dos mais terríveis cenários, em um esforço de denunciar o custo real da guerra no contexto moderno. Mas ela também é a esposa e mãe que deixa para trás marido e duas filhas jovens cada vez que viaja para uma nova zona de combate. Depois de uma experiência de quase-morte durante o registro de um ritual de uma mulher-bomba, seu marido Marcus (Nikolaj Coster-Waldau) lançalhe um ultimato: desistir da profissão perigosa ou perder a família com a qual ela pode contar sempre que retorna de cada viagem a trabalho. No entanto, Rebecca, convicta de que suas fotos podem fazer diferença, permanece com a sua determinação, o que dificulta que ela se afaste completamente de seu trabalho. Com uma oferta para fotografar um campo de refugiados no Quênia, um lugar supostamente tão seguro que sua filha Steph (Lauryn Canny) tem permissão para se juntar a ela, Rebecca fica cara a cara com o risco que corre cada vez que entra nas áreas de conflito.

Palavras-chave: Saúde mental; Suicídio; Comunicação; Fotografia; Relações familiares; Conflito Familiar, Cinema como assunto.

\section{Synopsis}

Rebecca (Juliette Binoche) is one of world's top war photojournalists, capturing dangerous and chilling images in the most dire landscapes, all in an effort to shed light on the real cost of modern war. But she's

i A sinopse em inglês foi extraída do site oficial do filme, e as versões em português e em espanhol foram realizadas pelos autores. [acesso 09 de janeiro de 2015]. Disponível em: http://1000timesgoodnight.com/\#synopsis. 
also a wife and mother, leaving behind a husband and two young daughters every time she travels to a new combat zone. After a near-death experience chronicling the ritual of a female suicide bomber, husband Marcus (Nikolaj Coster-Waldau) levels an ultimatum: give up the dangerous profession or lose the family she counts on being there when she returns from each assignment. Yet the conviction that her photos can make a difference keeps pulling at Rebecca's resolve, making it difficult for her to walk away entirely. With an offer to photograph a refugee camp in Kenya, a place allegedly so safe that daughter Steph (Lauryn Canny) is allowed to join her, Rebecca comes face to face with just how much she risks each time she steps back into the fray.

Keywords: Mental health; Suicide; Communication; Photography; Family relations; Family conflict.

\section{Sinopsis}

Rebecca (Juliette Binoche) es una de las más prestigiosas fotoperiodistas de guerra en el mundo, famosa por registrar imágenes peligrosas y aterradoras en los más terribles escenarios, en un esfuerzo por tratar de informar el costo real de la guerra en el contexto moderno. Pero ella también es esposa y madre, que deja a su esposo y a sus dos jóvenes hijas cada vez que viaja a una nueva zona de combate. Después de una experiencia de casi-muerte durante el registro de un ritual de una mujer suicida, su marido Marcus (Nikolaj Coster-Waldau) le da un ultimátum: o renuncia a la profesión peligrosa o pierde a la familia con la cual siempre puede contar al volver de un viaje de trabajo. Sin embargo, la convicción de que sus fotos pueden marcar la diferencia la impulsa a permanecer en su determinación, lo que hace que sea difícil para ella alejarse por completo de su trabajo. Con una oferta de sacar fotos en un campo de refugiados en Kenia, en un espacio supuestamente tan seguro que permite que su hija Steph (Lauryn Canny) pueda unirse a ella, Rebecca se encuentra cara a cara con el riesgo que corre cada vez que retoma su profesión y vuelve a trabajar en zonas de conflicto.

Palabras clave: Salud mental; Suicidio; Comunicación; Fotografía; Relaciones Familiares; Conflicto familiar.

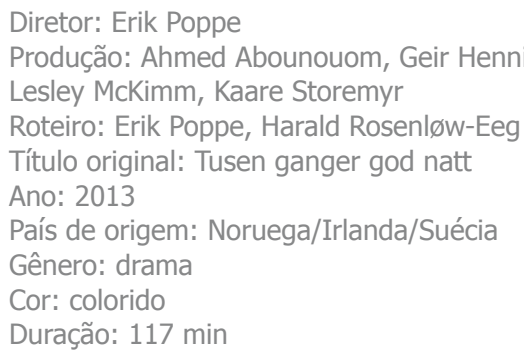




\section{Mil Vezes Boa Noite}

Filme dirigido pelo norueguês Erik Poppe, Mil Vezes Boa Noite venceu, entre outros, o Grande Prêmio Especial do Júri no Festival Internacional de Cinema de Montreal. A personagem principal, Rebecca, uma fotógrafa reconhecida por registrar cenas realísticas e impactantes de conflitos sociais, é vivida por Juliette Binoche, em uma atuação impecável. Curiosamente, vale ressaltar que o próprio Erik Poppe foi fotógrafo jornalístico do jornal Verdens Gang e da agência Reuters de notícias, cobrindo, inclusive, conflitos internacionais em várias partes do planeta ${ }^{1}$.

Como tema central, o filme aborda o drama familiar que a ausência de Rebecca de sua casa impõe a ela própria e à sua família, já extenuadas pelo medo da morte e pela necessidade de enfrentamento de tragédias que envolvem a protagonista a cada uma de suas viagens a trabalho.

A cena de abertura do filme é a representação de um funeral no qual mulheres fazem orações e choram em volta de uma cova na qual jaz um corpo feminino. Porém, o público é surpreendido - e, talvez, até mesmo Rebecca - quando o suposto cadáver levanta-se do túmulo, uma vez finda essa etapa do ritual de preparação de uma mulher-bomba. Na sequência, esta mulher-bomba - já uma sepulta - é minuciosamente equipada com coletes de explosivos e cuidadosamente vestida para cumprir sua missão. Movida pela necessidade de registrar tal situação, a fotógrafa solicita ao grupo que preparou a missão que lhe dê permissão para acompanhar a mulher em seu trajeto até o alvo - destino final. Ao ver-se prestes a uma inspeção policial, Rebecca sai tempestuosamente do veículo. Essa intervenção, que acaba por antecipar o momento da explosão da mulher-bomba, matando inúmeros transeuntes (além dela própria, obviamente), é registrada sofregamente pela fotógrafa já ferida no conflito. A partir deste acidente, muda-se o foco para um outro conflito: Rebecca retorna ao lar.

Nas primeiras cenas do reencontro da fotógrafa com o marido Marcus (vivido por Nikolaj Coster-Waldau), os impactos emocionais ocasionados pela tensão de uma família que abriga uma pessoa dedicada a registrar de perto zonas de conflito vêm à tona. Em uma discussão com Rebecca, o esposo menciona seu terror de atender a telefonemas, uma vez que estes podem anunciar sua morte ou externarem solicitações de resgate da fotógrafa após algum acidente grave, como o que ocorreu na cena da explosão da mulherbomba. Sua filha adolescente, Steph (vivida por Lauryn Canny) manifesta, em seu comportamento arredio, dificuldades para entender o tipo de vida e de trabalho que a mãe escolheu para si, e a ausência da mulhermãe e o medo da perda invadem seu cotidiano. A caçula, Lisa (Adrianna Cramer Curtis), de modo inocente percebe as viagens da mãe como períodos de distância/ausência recompensados por presentes que Rebecca traz de suas viagens, mas também sofre com a situação vivenciada em sua família.

Premida por esse cenário familiar, Rebecca, que se percebe como principal responsável pelo sofrimento em seu lar, decide encerrar sua trajetória como fotógrafa de guerra, a despeito de, em conversas com sua editora, ainda desejar que as fotos do episódio com a mulher-bomba sejam publicadas no periódico para o qual trabalha. Mas, no decorrer dos dias, Steph, envolvida por um misto de fascínio, curiosidade, repulsa e atração pelo trabalho da mãe, está dedicada a uma tarefa escolar sobre a África ao passo que a fotógrafa é convidada por um editor para trabalhar em uma área considerada pacífica naquele continente. Mesmo tendo se negado, inicialmente, a fazer o trabalho, pressionada pelo drama familiar, pela crise profissional que nela se instala após a decisão de não mais fotografar áreas de conflito, estimulada por Marcus a se reaproximar de sua filha adolescente, Rebecca realiza a viagem profissional. Todavia, uma situação inesperada de conflito acontece, enredando novamente a fotógrafa em sua paixão pelos registros de guerras. No afã de registrar mais um conflito, a fotógrafa envia sua filha para um lugar seguro na companhia do responsável pelo convite de trabalho, mas, a despeito disso, a adolescente é exposta ao medo e ao desespero intensos, o que acirra as rupturas em sua estrutura familiar. Tal situação faz Rebecca dividir-se emocional e definitivamente entre sua família e seu forte impulso por registrar situações de guerra. 
Essa trama familiar segue em seus altos e baixos, sem que o autor queira solucionar ou dar respostas aos espectadores sobre qual seria a melhor decisão existencial para a protagonista - dedicação à família ou à profissão.

Mas, para além dos imbróglios familiares do filme, este texto pretende chamar a atenção para questões afetas ao profissional fotógrafo de guerra, na tentativa de compreender algumas das razões que levam esses trabalhadores a executarem esse tipo de registro - como fizeram, na não ficção, o próprio Erik Poppe e o intrigante Robert Capa. Este último, nascido Endre Friedmann, em 22 de outubro de 1913, adotou o nome de Robert Capa e foi um dos mais célebres fotógrafos de guerra. Morreu aos 40 anos, em 25 de maio de 1954, após pisar em uma mina terrestre durante a cobertura da Guerra da Indochina, para a revista Life, em Thai-Binh. Capa registrou conflitos na primeira metade do século XX, entre eles, a Guerra Civil Espanhola, a Segunda Guerra Sino-Japonesa, a Segunda Guerra Mundial na Europa (em Londres, na Itália, a Batalha da Normandia em Omaha Beach, e a libertação de Paris), na África do Norte, a Guerra árabe-israelense de 1948 e a Primeira Guerra da Indochina ${ }^{2}$.

Entre as reflexões suscitadas por meio do filme, foi possível identificar características que podem representar algumas das diferentes motivações que impulsionam esses fotógrafos a registrarem guerras e conflitos. Ficou evidente na trama a necessidade de denunciar, por meio do olhar da fotógrafa Rebecca, o sofrimento humano em lugares e situações em que tais dores são banalizadas. Afinal, mesmo sabendo-se que guerra é lugar de morte, de feridas, de dor, assim como é conhecido o fato de que em diversos lugares do mundo as populações sofrem diferentes mazelas sociais e políticas geradas por contendas, as imagens produzidas por fotógrafos de zonas de conflito pretendem estampar de forma contundente o dia a dia desses locais. Sem elas, poder-se-ia dizer que tais conflitos são conhecidos, mas não são vistos. Deste modo, é possível pensar que fotógrafos de guerra buscam esquadrinhar o cotidiano vivido por pessoas submetidas a tais situações e mostrá-las como que desvelando algo que estaria encoberto. Por meio das lentes de suas câmeras, o fotógrafo de guerra transmite o que há de humano em meio aos conflitos: o desespero, as perdas, as histórias de vida, os sentimentos, a capacidade de adaptação do ser humano, a criatividade e, até mesmo, momentos de descontração em meio ao caos - o que é notável nas obras de Capa ${ }^{3}$.

A protagonista do filme afirma que suas fotos são retratos do que ela vê [em sua humanidade]. Outra de suas falas marcantes é a que expõe seu sentimento de raiva como a motivação para fazer fotos de guerra. Isto remete, por um lado, a uma inconformidade com as disputas de poder ocorridas nos conflitos, na maioria das vezes de modo desigual, nos quais os menos favorecidos sofrem as maiores consequências. Por outro, impõe à personagem principal vivenciar sua própria raiva, por vezes encoberta, em relação ao não dito ou não feito de sua vida privada. Ao se defrontar com injustiças sociais e políticas, podemos conjecturar que os fotógrafos de guerra encontram em suas lentes um veículo de protesto e denúncia. A personagem Rebecca demonstra a sua indignação e o seu repúdio pela impunidade e utiliza suas fotos como instrumento de mobilização social a fim de obter socorro e auxílio.

Mas uma nova dimensão, também conflituosa em Rebecca, conduz nosso olhar para questões éticas precípuas ligadas às imagens que, na atualidade globalizada, são espalhadas ao redor do mundo em segundos. Em certo momento do filme, a fotógrafa se questiona acerca do por que, mesmo gravemente ferida na explosão promovida pela mulher-bomba, ela prosseguiu obstinadamente em seu ofício e realizou fotos durante seu estertor. Esta é uma questão aberta - que não pretendia ser fechada pelo roteiro do filme, mas acerca da qual podem ser levantadas questões (pautadas em uma psicologia da protagonista) que se atenham a um impulso de ver, verificar, registrar, aproximar-se ao máximo da cena e da verdade. Ou, no dizer de Robert Capa: "Se sua foto não está boa o suficiente, você não está perto o suficiente”4.

Aqui, consideramos que a cena fotografada é a de um ato de autoextermínio. Mesmo tendo em vista que há uma missão a cumprir, impelida por crenças religiosas e/ou ideológicas (não cabendo neste texto julgamento de valor acerca do ato praticado por uma mulher-bomba), o que se tem como elemento defla- 
grador no trabalho da fotógrafa no impactante contexto de abertura do filme é um ato suicida, e este é um dilema ético de especial importância quando se trata de interações da sociedade com as mídias atuais. Vale mencionar, porém, o conceito de suicídio altruísta (ou filantrópico) ${ }^{5}$, formulado por Durkheim, no qual é dever do suicida desembaraçar-se de uma vida insuportável, sacrificando a própria vida em função de um ideal maior. Neste tipo de ato suicida, a integridade do indivíduo confunde-se com a externalidade, com o dever de algo regido pela sociedade, como uma missão. E, portanto, suicidar é cumprir parte de uma tarefa social que lhe foi imposta por regras sociais.

A possibilidade de ocorrência de novos atos de autoaniquilação motivados pelo impacto da veiculação de eventos suicidas, o chamado "efeito Werther", é uma preocupação presente quando se pensa a questão da prevenção do suicídio no mundo.

\section{Segundo a organização Mundial da Saúde (OMS:}

Uma das primeiras associações conhecidas entre os meios de comunicação de massa e o suicídio vem da novela de Goethe, Die Leiden des Jungen Werther (Os Sofrimentos do Jovem Werther), publicada em 1774. Nesta novela, o herói se dá um tiro após um amor mal sucedido. Logo após sua publicação, começaram a surgir na Europa vários relatos de jovens que cometeram o suicídio usando o mesmo método. Isto resultou na proibição do livro em diversos lugares. Este fenômeno originou o termo "Efeito Werther", usado na literatura técnica, para designar a imitação de suicídios ${ }^{6}$.

Em seu manual para profissionais da mídia, a OMS não apenas alerta para esse efeito, como também, propala orientações acerca do que deve e do que não deve ser veiculado pela mídia em relação ao suicídio. Essas orientações, em sua forma resumida, são:

O que fazer:

- Trabalhar em conjunto com autoridades de saúde na apresentação dos fatos.

- Referir-se ao suicídio como suicídio “consumado”, não como suicídio "bem sucedido”.

- Apresentar somente dados relevantes, em páginas internas de veículos impressos.

- Destacar as alternativas ao suicídio.

- Fornecer informações sobre números de telefones e endereços de grupos de apoio e serviços onde se possa obter ajuda.

- Mostrar indicadores de risco e sinais de alerta sobre comportamento suicida.

\section{O que NÃO fazer:}

- Não publicar fotografias do falecido ou cartas suicidas.

- Não informar detalhes específicos do método utilizado.

- Não fornecer explicações simplistas.

- Não glorificar o suicídio ou fazer sensacionalismo sobre o caso.

- Não usar estereótipos religiosos ou culturais.

- Não atribuir culpas ${ }^{6}$

O final do filme é marcado pela apresentação do trabalho escolar da filha adolescente da protagonista. Nele, a menina reconhece a importância e exalta o papel fundamental do fotógrafo de áreas de conflito (ofício de sua mãe), caracterizando-o como um trabalho que alcança espaços de sofrimento e que, com seus registros, apresenta a situação de vulnerabilidade na qual se encontram inúmeras pessoas, tornando-as visíveis ao mundo.

É interessante notar, por outro lado, que, talvez como solução ética abraçada pelo autor, talvez por mera coincidência, a despeito da exaltação da profissão e da defesa feita por Steph acerca do desvelamento promovido pelo fotojornalismo de guerra, a editora do jornal para o qual Rebecca trabalha, ao fim e ao cabo, decide não publicar as imagens feitas pela fotógrafa no episódio da mulher-bomba. 
Antes de encerrar, para ampliar ainda mais essa discussão, cabe mencionar o conflito expresso, inclusive, na escolha do título do filme. Em uma primeira tentativa, esta película chamar-se-ia Grenade (explosivo, granada) e, assim, a nosso ver, seria apresentada como sendo conduzida por seu caráter bélico 7 . Mais tarde, a opção por Mil Vezes Boa Noite envolve a obra em uma bruma de conflito e humanidade posto que alude à fala de Julieta a Romeu em uma noite de despedida e de paixão:

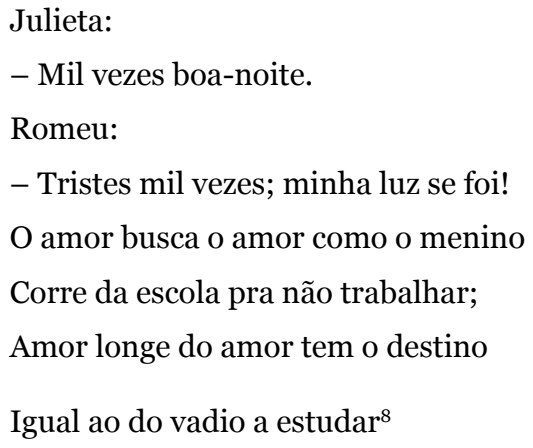

Observa-se que, mesmo (e paradoxalmente) se tratando de fotografia, a "luz se foi!" e o obscuro da dor e do conflito - seja em relação ao contexto familiar privado da presença da mulher-mãe, seja em relação às dimensões éticas afetas à publicação de fotos de guerra - ganharam espaço e intitularam essa obra.

Por fim, Mil Vezes Boa Noite possibilita uma reflexão acerca da função social do fotojornalismo e de sua capacidade de comunicar cenas (montadas ou não) indizíveis de forma textual, tais como expressões faciais ou cenas de sofrimento humano em geral, inscritas em um contexto histórico que amplia o horizonte de sua compreensão. Possibilita também uma visada do âmbito dos fotógrafos de zonas de conflito e de alguns aspectos que circundam este campo, como o desafio de cobrir uma situação de guerra, a publicação de fotos-denúncia, e a necessidade de reflexão acerca de questões éticas, dada a relevância que este tipo de trabalho adquire na sociedade.

\section{Referências}

1. IMBd. Erik Poppe. Biography [internet]. [acesso em 06 de janeiro de 2015]. Disponível em: http://www. imdb.com/name/nm0691547/bio?ref $=$ nm ov bio sm

2. Magnum Photos. Robert Capa. Profile. [acesso em 12 de janeiro de 2015]. Disponível em: http://www. magnumphotos.com/C.aspx?VP3=CMS3\&VF=MAGO31 9 VForm\&ERID=24KL53535

3. Capa R. Ligeiramente fora de foco. São Paulo: Cosac Naify Edições; 2010.

4. Laconte LO. A Exaltação da Guerra: uma análise da cobertura fotográfica da Segunda Guerra Mundial realizada pela Revista da Semana. Rev Anag. 2015; 9(1)1-18. [acesso em 09 de janeiro de 2015]. Disponível em: http://www.revistas.univerciencia.org/index.php/anagrama/article/viewFile/8839/8036

5. Durkheim E. O suicídio: estudo de sociologia. São Paulo: Martins Fontes; 2000.

6. OMS. Organização Mundial da Saúde. Departamento de Saúde Mental. Transtornos Mentais e Comportamentais. Prevenção do Suicídio: Um manual para profissionais da mídia [internet]. Genebra: 2000. [acesso em 06 de janeiro de 2015]. Disponível em: http://www.who.int/mental health/ prevention/suicide/en/suicideprev media_port.pdf

7. IMBd. Mil Vezes Boa Noite. Trivia. [acesso em 06 de janeiro de 2015]. Disponível em: http://www.imdb. com/title/tt2353767/trivia?ref =tt trv trv

8. Shakespeare W. Romeu e Julieta. Rio de Janeiro: Nova Fronteira; 2011. 